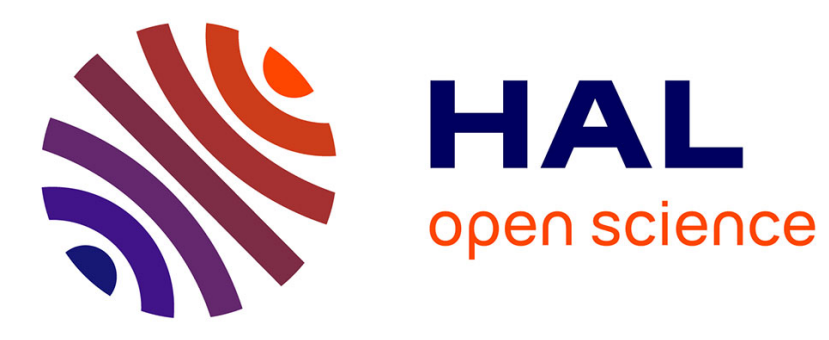

\title{
Phosphorus-doped (113) CVD diamond: A breakthrough towards bipolar diamond devices
}

Marie-Amandine Pinault-Thaury, Solange Temgoua, Rémi Gillet, Hakima

Bensalah, Ingrid Stenger, François Jomard, Riadh Issaoui, Julien Barjon

\section{- To cite this version:}

Marie-Amandine Pinault-Thaury, Solange Temgoua, Rémi Gillet, Hakima Bensalah, Ingrid Stenger, et al.. Phosphorus-doped (113) CVD diamond: A breakthrough towards bipolar diamond devices. Applied Physics Letters, 2019, 114 (11), pp.112106. 10.1063/1.5079924 . hal-02407526

\author{
HAL Id: hal-02407526 \\ https://hal.science/hal-02407526
}

Submitted on 11 Dec 2020

HAL is a multi-disciplinary open access archive for the deposit and dissemination of scientific research documents, whether they are published or not. The documents may come from teaching and research institutions in France or abroad, or from public or private research centers.
L'archive ouverte pluridisciplinaire $\mathbf{H A L}$, est destinée au dépôt et à la diffusion de documents scientifiques de niveau recherche, publiés ou non, émanant des établissements d'enseignement et de recherche français ou étrangers, des laboratoires publics ou privés. 


\section{Phosphorus-doped (113) CVD diamond: A breakthrough towards bipolar diamond devices}

Cite as: Appl. Phys. Lett. 114, 112106 (2019); https://doi.org/10.1063/1.5079924

Submitted: 05 November 2018 . Accepted: 02 March 2019. Published Online: 21 March 2019

Marie-Amandine Pinault-Thaury, Solange Temgoua, Rémi Gillet, Hakima Bensalah, Ingrid Stenger,

François Jomard, Riadh Issaoui, and Julien Barjon

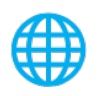

\section{Applied Physics Reviews} Now accepting original research 


\title{
Phosphorus-doped (113) CVD diamond: A breakthrough towards bipolar diamond devices
}

\author{
Cite as: Appl. Phys. Lett. 114, 112106 (2019); doi: 10.1063/1.5079924 \\ Submitted: 5 November 2018 • Accepted: 2 March 2019 . \\ Published Online: 20 March 2019

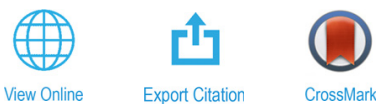

Marie-Amandine Pinault-Thaury, ${ }^{1, a)}$ Solange Temgoua, ${ }^{7}$ Rémi Gillet, ${ }^{7}$ Hakima Bensalah, ${ }^{7}$ Ingrid Stenger, François Jomard, Riadh Issaoui, ${ }^{2}$ and Julien Barjon

\begin{abstract}
AFFILIATIONS
${ }^{7}$ Groupe d'Etude de la Matière Condensée (GEMaC-UMR8635), CNRS, Université de Versailles St-Quentin-En-Yvelines (UVSQ), Université Paris-Saclay, 45 av des Etats Unis, 78035 Versailles Cedex, France

${ }^{2}$ Laboratoire des Sciences des Procédés et des Matériaux (LSPM), Université Paris 13, Sorbonne Paris Cité, CNRS, 93430 Villetaneuse, France
\end{abstract}

${ }^{a)}$ Author to whom correspondence should be addressed: marie-amandine.pinault-thaury@uvsq.fr

\begin{abstract}
Among wide bandgap semiconductors, diamond presents physical properties particularly suited for high performance power electronic devices. Growth and doping of chemical vapor deposited (CVD) diamond have been mainly optimized in the conventional (100) crystal orientation, highly studied on (111) surfaces and recently initiated on (113). This last orientation seems very promising, as is shown for intrinsic and p-type doped diamonds. In this work, we report the growth of CVD phosphorus doped diamond films on (113)-oriented substrates. The (113) homoepitaxial layers present a phosphorus content in the range of $7.2 \times 10^{16}$ up to $4.5 \times 10^{19}$ at $/ \mathrm{cm}^{3}$ for thicknesses between $0.6 \mu \mathrm{m}$ and $4 \mu \mathrm{m}$. The high quality and the full incorporation of phosphorus into donor sites found for the (113) crystal orientation open new architecture possibilities for bipolar diamond devices.
\end{abstract}

Published under license by AIP Publishing. https://doi.org/10.1063/1.5079924

For high power electronics, diamond presents unbeatable physical properties compared to other wide bandgap semiconductors. ${ }^{1}$ Similar to $\mathrm{ZnO}$ and $\mathrm{GaN}$ semiconductors, its doping is asymmetric. The p-type doping of diamond with boron in substitution for carbon is fairly easy and now technologically mature. ${ }^{2-4}$ On the contrary, ntype conductivity of diamond is difficult to realize and remains a major issue for the fabrication of diamond-based bipolar devices. Recent studies performed using chemical vapor deposition (CVD) ${ }^{5}$ or even high pressure high temperature $(\mathrm{HPHT})^{6,7}$ growth processes show that n-type doping of diamond is still an active research topic.

The conventional crystalline orientations used for $n$-type doping are (100) and (111). The (100) diamond substrates are however preferred because they are more easily polished and less expensive to produce. Diamond homoepitaxial layers are usually grown by microwave plasma-assisted chemical-vapor-deposition (MPCVD), such an outof-equilibrium growth technique being necessary for the doping of synthetic diamond. Due to easy crystalline defect formation on (111) surfaces, better electronic properties are generally observed on (100) homo-epilayers. 8

Even if phosphorus is quite a deep donor with an ionization energy of $0.6 \mathrm{eV},{ }^{9}$ it gives the highest n-type conductivities reported so far in diamond. ${ }^{10-13}$ The phosphorus incorporation efficiency exceeds $5 \%{ }^{14}$ to reach up to $18 \%$ in the (111) orientation, ${ }^{15}$ while it is only $0.026 \%$ in the (100) orientation that is 1000 times lower. ${ }^{8,16}$ In addition, the maximum phosphorus content saturates at a few $10^{20}$ at $/ \mathrm{cm}^{3}$ in the (111) orientation ${ }^{17}$ but does not exceed a few $10^{18} \mathrm{at} / \mathrm{cm}^{3}$ in the (100) orientation. ${ }^{16,18,19}$ The capability of phosphorus atoms to incorporate as donors in substitutional sites during the MPCVD growth is evaluated through the fraction of phosphorus donors, $\mathrm{N}_{\mathrm{D}} /[\mathrm{P}]$ (where $\mathrm{N}_{\mathrm{D}}$ is the donor concentration and $[\mathrm{P}]$ the phosphorus concentration). While phosphorus atoms get incorporated in substitutional sites in (111) homo-epilayers rather easily, ${ }^{20}$ it is difficult to obtain $\mathrm{N}_{\mathrm{D}} /[\mathrm{P}]$ $=100 \%$ on (100) orientation. Actually, the growth of (100) n-type diamond with phosphorus requires misoriented substrates ${ }^{16}$ with a specific and narrow window of growth parameters.

In 2008, Silva et al. ${ }^{21}$ observed that $\{113\}$ faces occur during (100) diamond epitaxy, at the corner of the diamond plate, under standard CVD growth conditions. Such $\{113\}$ facets are of F-type: with smooth and low growth by sept flow. The (113) orientation being a stable crystal plane under standard CVD growth conditions may yield to the largest usable surface area, one of the most important issues for power electrics. Recently, the deposition of diamond films has been extended 
to the (113) orientation. ${ }^{22,23}$ It appears that for p-type doping with boron, such an orientation presents boron incorporation in substitutional sites during growth and high crystalline quality for thin to thick layers. Furthermore, Tallaire et al. even showed the feasibility of highly boron-doped free-standing (113) plates. As a result, this orientation seems promising for the fabrication of vertical power devices made of diamond. $^{24}$

In this study, we investigate the phosphorus doping on (113) oriented substrates by growing homo-epilayers by MPCVD. We show the feasibility of phosphorus doping with full incorporation in donor sites and compare our results with the ones obtained in conventional orientations.

Phosphorus-doped homoepitaxial layers have been grown on (113) type $I b$ high pressure high temperature (HPHT) diamond substrates. These were obtained by laser cutting and polishing larger size (100)-oriented diamond crystals, resulting in a cylindrical shape with a diameter of $2 \mathrm{~mm}$ and a thickness of $0.5 \mathrm{~mm} .^{22,23}$ Their miscut angle with respect to the [113] direction has been measured by $\mathrm{X}$ ray diffraction and presents a value of $\sim 1.5^{\circ}$ for all substrates. To remove any organic and metallic contaminations from the surface, the substrates were chemically cleaned before introduction into the growth reactor. ${ }^{12}$

The growth has been performed in a laboratory-built metallic reactor allowing microwave plasma chemical vapor deposition (MPCVD) associated with the metal-organic CVD technology for doping with a liquid phosphorus precursor. ${ }^{11}$ The growth was carried out with a mixture of $\mathrm{H}_{2}$ and $\mathrm{CH}_{4}$ having both $9 \mathrm{~N}$ purity. The substrate temperature was in the range of $900{ }^{\circ} \mathrm{C}-920^{\circ} \mathrm{C}$, as measured with a dual-wavelength Williamson pyrometer. Different microwave powers and total gas flows and pressures were used (see Table I). The dopant source was tertiary butyl-phosphine $\left(\mathrm{TBP}: \mathrm{C}_{4} \mathrm{H}_{11} \mathrm{P}\right)$ vapor with $6 \mathrm{~N}$ purity and was diluted in hydrogen. The phosphorus concentration in the gas phase, evaluated by the $[\mathrm{P}] /[\mathrm{C}]_{\text {gas }}$ ratio, was adjusted to $0 \%, 0.12 \%, 5 \%$, and $12 \% .[\mathrm{P}] /[\mathrm{C}]_{\text {gas }}=0 \%$ stands for the situation where no TBP is injected into the reactor. Actually, once phosphorus precursors have been introduced into the reactor, they contaminate the growth chamber and phosphorus keeps incorporating into forthcoming diamond layers, even without TBP injection. This effect is known as the "memory effect" of the reactor. In this work, the layers grown with $[\mathrm{P}] /[\mathrm{C}]_{\mathrm{gas}}=0 \%$ indeed contain phosphorus and are called "non-intentionally doped" (NID) layers. Three samples were grown with a single epilayer: one intentionally doped (sample A) and the other two NID (samples B and C). One multilayer sample (D) was doped intentionally with increasing steps of TBP concentration in the gas phase (D1, D2, and D3). All the growth conditions are summarized in Table I together with the main characteristics of the homoepilayers. We emphasize that the growth conditions investigated for the (113) orientation on sample A are identical to (100) homo-epilayer growth conditions. ${ }^{8,25}$ On the contrary, in the case of other three samples $(B, C$, and D), they are similar to those generally used for (111) layers. ${ }^{11,15}$

The phosphorus concentration $[\mathrm{P}]$ together with the thickness of the epilayers has been measured by secondary ion mass spectrometry (SIMS) on CAMECA IMS7f equipment. The primary beam consists of a $\mathrm{Cs}^{+}$ion beam with an energy of $10 \mathrm{keV}$ and a current of $60 \mathrm{nA}$. Secondary ions are detected in the negative mode leading to $15 \mathrm{keV}$ of interaction energy of the primary $\mathrm{Cs}^{+}$ions and to $23.6^{\circ}$ of the incidence angle with respect to the normal of the sample. The sputtering rate was around $4 \AA / \mathrm{s}$. To limit the edge effects on the $150 \times 150 \mu \mathrm{m}^{2}$ SIMS crater, the analyzed zone is restricted to a diameter of $33 \mu \mathrm{m}$. A Dektak8 stylus contact profiler instrument allows measuring the depth of the resulting crater. The secondary ions of masses 12 (C) and 31 (P) were detected. The analysis was done at a low mass resolution. The quantification of the phosphorus concentration in our diamond samples was made, thanks to the ion-implanted diamond standard with a known dose of phosphorus. This method typically gives the phosphorus concentration of the epilayers with a $10 \%$ relative uncertainty.

The surface morphology was investigated by Atomic Force Microscopy (AFM). AFM measurements were performed using a Bruker AXS Dimension 3100 in the tapping mode with a Bruker RTESP300 antimony-doped silicon probe having a resistivity range of $0.010-0.025 \Omega \cdot \mathrm{cm}$, a resonance frequency of $300 \mathrm{kHz}$ and a spring constant of $40 \mathrm{~N} \cdot \mathrm{m}^{-1}$. AFM images are recorded on $2 \times 2 \mu \mathrm{m}^{2}$ surfaces.

Cathodoluminescence (CL) spectroscopy was performed on the (113) epilayers to evaluate the optical activity of the phosphorus

TABLE I. Growth conditions and main characteristics of the phosphorus-doped CVD (113) diamond films. Note that the phosphorus memory effect increased after sample B.

\begin{tabular}{|c|c|c|c|c|c|c|}
\hline \multirow[b]{2}{*}{ Sample } & \multirow[b]{2}{*}{$\mathrm{A}$} & \multirow[b]{2}{*}{$\mathrm{B}$} & \multirow[b]{2}{*}{$\mathrm{C}$} & \multicolumn{3}{|c|}{$\mathrm{D}$} \\
\hline & & & & D 1 & D 2 & D 3 \\
\hline Pressure (mbar) & 75 & 50 & 50 & 50 & 50 & 50 \\
\hline Microwave power (W) & 230 & 420 & 410 & 410 & 410 & $360-420$ \\
\hline Total gas flow (sccm) & 400 & 1000 & 1000 & 1000 & 1000 & 1000 \\
\hline$[\mathrm{C}] /\left[\mathrm{H}_{2}\right](\%)$ & 1.8 & 0.05 & 0.05 & 0.05 & 0.05 & 0.05 \\
\hline$[\mathrm{P}] /[\mathrm{C}]_{\mathrm{gas}}(\%)$ & 0.12 & 0 & 0 & 0 & 5 & 12 \\
\hline $\mathrm{T}_{\text {growth }}\left({ }^{\circ} \mathrm{C}\right)$ & 930 & 900 & 910 & 920 & 920 & $920-900$ \\
\hline Duration (h) & 1.5 & 6 & 28 & 3 & 3 & 9 \\
\hline Thickness (nm) & 1650 & 595 & 3950 & 420 & 460 & 1170 \\
\hline $\mathrm{R}_{\text {growth }}(\mathrm{nm} / \mathrm{h})$ & 1100 & 99 & 141 & 140 & 153 & 130 \\
\hline$\eta=\left([\mathrm{P}] /[\mathrm{C}]_{\text {solid }}\right) /\left([\mathrm{P}] /[\mathrm{C}]_{\mathrm{gas}}\right)$ & 2.2 & $\mathrm{n} / \mathrm{a}$ & $\mathrm{n} / \mathrm{a}$ & $\mathrm{n} / \mathrm{a}$ & 0.08 & 0.07 \\
\hline$[\mathrm{P}]\left(\mathrm{at} / \mathrm{cm}^{3}\right)$ & $4.7 \times 10^{18}$ & $7.2 \times 10^{16}$ & $3.2 \times 10^{19}$ & $3.1 \times 10^{19}$ & $3.8 \times 10^{19}$ & $4.5 \times 10^{19}$ \\
\hline RMS (nm) & 27.6 & 1.6 & 7 & $\mathrm{n} / \mathrm{a}$ & $\mathrm{n} / \mathrm{a}$ & $\mathrm{n} / \mathrm{a}$ \\
\hline
\end{tabular}


dopants and estimate the crystalline quality of the layers. This technique is used to quantify the phosphorus donor concentration $\mathrm{N}_{\mathrm{D}}$, whatever be the concentration of compensating acceptors $\mathrm{N}_{\mathrm{A}}$. It is based on the intensity ratio between the bound and free exciton luminescence signals at low temperatures $(10 \mathrm{~K})$, following the method detailed in Ref. 26 with a description of the experimental set-up. The samples were cooled down at $10 \mathrm{~K}$ in a JEOL7001F scanning electron microscope (SEM). Depending on the layer thickness, a $5 \mathrm{keV}$ or $10 \mathrm{keV}$ electron beam energy was used which corresponds, respectively, to $\sim 0.27$ and $0.87 \mu \mathrm{m}$ of the stopping depth for electrons.

The surfaces of the samples did not evidence any structural defects as pyramidal hillocks or non-epitaxial crystallites that are typical for low quality diamond growth. ${ }^{16}$ Figure 1 shows AFM images performed on the single epilayers. Sample A presents a high roughness with 3D growth-mode characteristics [Fig. 1(a)]. Samples B and C exhibit low surface roughness $(<7 \mathrm{~nm})$ with sawtooth features [Fig. 1(b)] and a step bunching growth process [Fig. 1(c)], respectively. This surface morphology is smoother than the one reached on (110) phosphorus-doped CVD diamond. ${ }^{27}$ Using (100)-like growth conditions for the (113) substrates produced rough layers with low crystalline quality, as confirmed by the weak CL signal recorded in the excitonic region for sample A (not shown here). This reveals that the (111)-like diamond growth conditions are better suited to grow (113) homoepitaxial diamond in our growth reactor and in the presence of phosphorus. This differs from our previously reported results on boron-doped (113) epilayers for which a wide range of growth conditions similar to those used on (100) led to smooth high-quality films. ${ }^{23}$

Figure 2(a) shows the SIMS depth profiles of the phosphorus content for the single epilayers (samples A, B, and C). We observe an abrupt incorporation of phosphorus at the layer-substrate interface together with a plateau of phosphorus concentration. We remind here that samples B and C are NID layers. Due to a series of intermediate experiments carried out in the reactor, the memory effect was modified between samples B and C leading to a higher non-intentional doping in sample $\mathrm{C}$. The phosphorus content in the single epilayers varies from $7.2 \times 10^{16}$ at $/ \mathrm{cm}^{3}$ up to $3.2 \times 10^{19} \mathrm{at} / \mathrm{cm}^{3}$. Note that the lowest value is also reached in the (110) orientation. ${ }^{27}$

In the following, the analysis of results will focus on the high quality (113) layers obtained under (111)-like growth conditions (samples B, C, and D). The growth rate of such (113) phosphorus doped

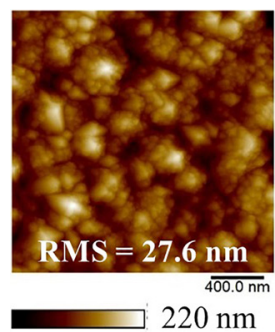

(a)

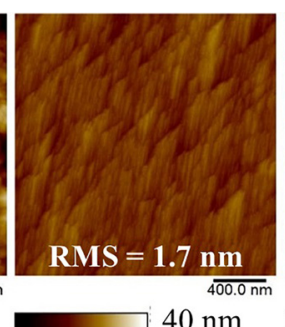

(b)
Sample A

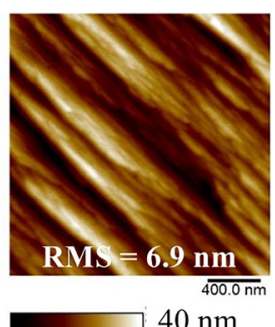

(c)

FIG. 1. AFM images of (a) sample A presenting a 3D surface morphology with a high roughness value (RMS $=27.6 \mathrm{~nm}$ ), (b) sample $B$ with a flat surface (RMS $=1.7 \mathrm{~nm})$ and $(\mathrm{c})$ sample $\mathrm{C}$ with low surface roughness $(\mathrm{RMS}=6.9 \mathrm{~nm})$.

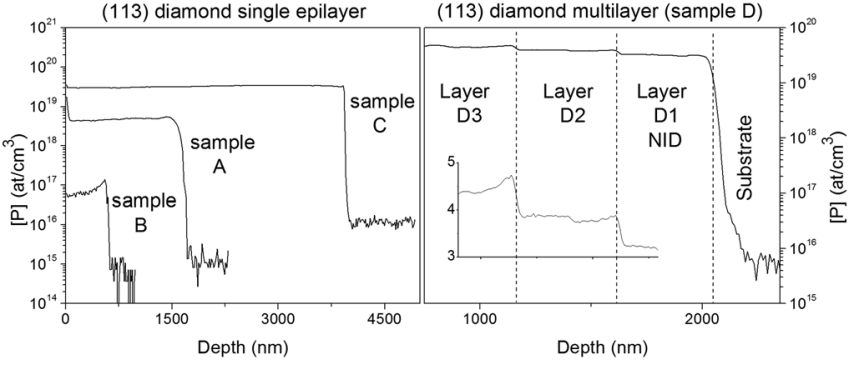

(a)

(b)

FIG. 2. SIMS depth profiles of (a) the diamond single epilayers and (b) the diamond multilayer grown on (113) substrates under different growth conditions (linear scale in the inset).

diamond layers is around $0.1 \mu \mathrm{m} / \mathrm{h}$, similar to that obtained on (111) diamond. ${ }^{11}$

The multilayer (sample D) is used to evaluate the phosphorus incorporation efficiency, $\eta=\left([\mathrm{P}] /[\mathrm{C}]_{\text {solid }}\right) /\left([\mathrm{P}] /[\mathrm{C}]_{\text {gas }}\right)$ on (113) diamond surfaces. The SIMS depth profile of its phosphorus concentration is shown in Fig. 2(b) over the first $1.3 \mu \mathrm{m}$. Three plateaus are clearly observed and correspond to the 3 layers grown with increasing $[\mathrm{P}] /[\mathrm{C}]_{\text {gas }}$ ratio. The first plateau that follows the substrate interface corresponds to D1 grown without TBP in the gas phase (NID). The phosphorus content measured in this first plateau gives an evaluation of the phosphorus memory effect in the reactor that reached $3.1 \times 10^{19} \mathrm{at} / \mathrm{cm}^{3}$. The second plateau is reached at $420 \mathrm{~nm}$ from the substrate interface and is marked with an increasing step from the first plateau. The phosphorus content is measured at $3.8 \times 10^{19}$ at $/ \mathrm{cm}^{3}$ and corresponds to $\mathrm{D} 2$ grown with $[\mathrm{P}] /[\mathrm{C}]_{\text {gas }}=5 \%$. The third plateau occurs at $880 \mathrm{~nm}$ from the substrate interface, and is also marked with an increasing step. The phosphorus concentration is of $4.5 \times 10^{19}$ at/ $\mathrm{cm}^{3}$ and corresponds to D3 grown with $[\mathrm{P}] /[\mathrm{C}]_{\text {gas }}=12 \%$. This value of phosphorus content is the maximum value reached on (113) surfaces in this study: $[\mathrm{P}]_{\max }{ }^{(113)}=4.5 \times 10^{19}$ at $/ \mathrm{cm}^{3}$ (epilayer D3). It is between the maximum solubility reported in the (100) and (111) conventional orientations: $[\mathrm{P}]_{\max }{ }^{(100)}=8 \times 10^{18}$ at $/ \mathrm{cm}^{316}<[\mathrm{P}]_{\max }{ }^{(113)}<$ $[\mathrm{P}]_{\max }^{(111)}=2.2 \times 10^{20} \mathrm{at} / \mathrm{cm}^{3}{ }^{16,17,28-30}$

The phosphorus incorporation efficiency $\eta$ was extracted from intentionally doped films of multilayers (D2 and D3 from sample D). It reaches $\sim 0.08 \%, 3$ times higher than the one obtained in the (100) orientation. The incorporation efficiency of phosphorus found for the (113) orientation is between the one reported for conventional (100) and (111) orientations: $\eta^{(100)}=0.026 \%{ }^{16}<\eta^{(113)}<\eta^{(111)}=18 \%{ }^{15}$

For the lowest (113) phosphorus-doped layer (sample B with $7.2 \times 10^{16} \mathrm{at} / \mathrm{cm}^{3}$ ), the CL spectrum in the excitonic region is shown in Fig. 3(a). The spectrum is dominated by two kinds of exciton recombinations: one at $5.27 \mathrm{eV}$, corresponding to the free exciton recombination, $\mathrm{X}_{\mathrm{TO}}$, and the other one at $5.19 \mathrm{eV}$, attributed to the donor bound exciton recombination, $\mathrm{P}^{0} \mathrm{X}_{\mathrm{TO}}$. Both recombinations are assisted by the emission of a transverse optical (TO) phonon. The no-phonon phosphorus-bound-exciton recombination $\mathrm{P}^{0} \mathrm{X}_{\mathrm{NP}}$ is also observed at $5.33 \mathrm{eV}$ together with the triplet fine structure, signature of donors in diamond. ${ }^{31}$ The line widths of $\mathrm{P}^{0} \mathrm{X}_{\mathrm{TO}}$, and $\mathrm{P}^{0} \mathrm{X}_{\mathrm{NP}}$ lines are, respectively, $9.3 \mathrm{meV}$ and $1.8 \mathrm{meV}$. The observation of these characteristics ${ }^{32,33}$ indicates that the crystallinity of the lightly phosphorus-doped (113) 


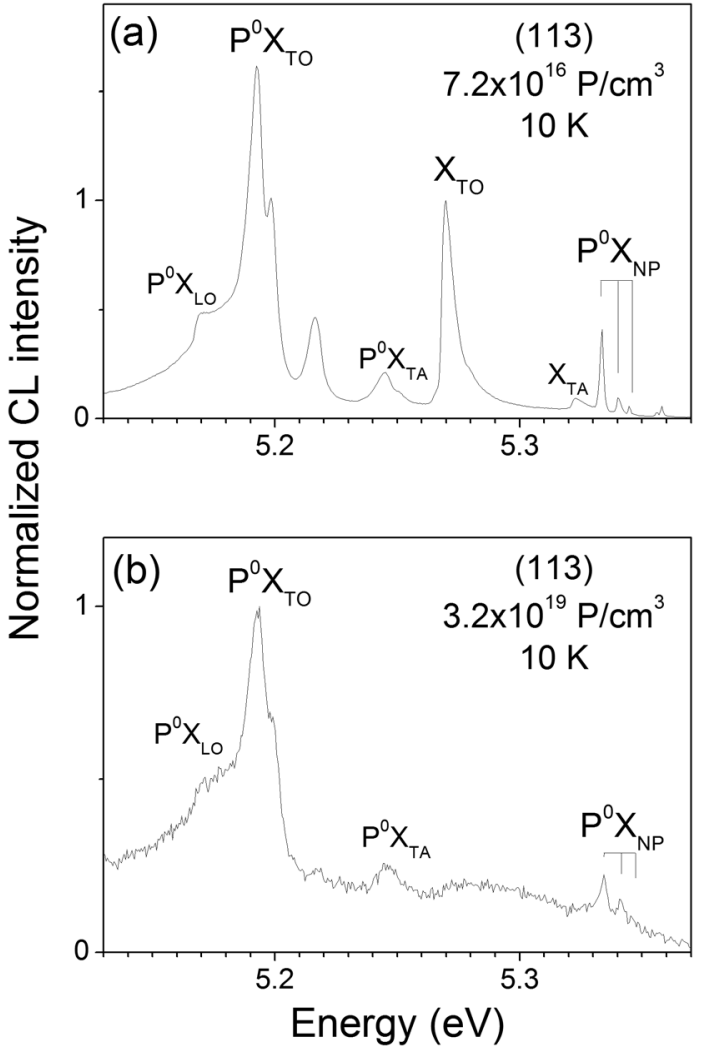

FIG. 3. Cathodoluminescence spectra in the excitonic region of the (113) phosphorus-doped epilayers presenting a phosphorus content of (a) $7.2 \times 10^{16}$ at/ $\mathrm{cm}^{3}$ (sample B) and (b) $3.2 \times 10^{19} \mathrm{at} / \mathrm{cm}^{3}$ (sample C). The spectra show narrow bound exciton $\mathrm{P}^{0} \mathrm{X}_{\mathrm{TO}}$ lines and non-phonon $\mathrm{P}^{0} \mathrm{X}_{\mathrm{NP}}$ lines proving the good quality of the (113) diamond layers over a wide range of phosphorus content.

epilayer is comparable to the best (100) and (111) n-type phosphorus-doped diamond layers $\left[12 \mathrm{meV}\right.$ and $2.4 \mathrm{meV},{ }^{8,34} 9 \mathrm{meV}$ and $2 \mathrm{meV}, 25,31,35$ respectively]. Such narrow lines point out the good crystalline quality of sample B.

The detection of the phosphorus bound exciton in sample B indicates that phosphorus atoms are located in substitutional sites, acting as donors. Using the quantification method, ${ }^{24}$ we found a donor concentration $\mathrm{N}_{\mathrm{D}}=7 \times 10^{16} \mathrm{at} / \mathrm{cm}^{3}$ in sample $\mathrm{B}$, while the phosphorus content in the layer is $[\mathrm{P}]=7.2 \times 10^{16} \mathrm{at} / \mathrm{cm}^{3}$. This means that $\mathrm{N}_{\mathrm{D}} /$ $[\mathrm{P}]$ is $\sim 100 \%$ in this sample. In other words, this reveals that, for such phosphorus content in the (113) orientation, almost all phosphorus impurities incorporate as donors.

For higher phosphorus content $\left(3.2 \times 10^{19} \mathrm{at} / \mathrm{cm}^{3}\right.$ for sample C), the spectrum shown in Fig. 3(b) is noisier and dominated by the phosphorus bound excitons, while the free exciton $\mathrm{X}_{\mathrm{TO}}$ intensity vanishes due to the higher phosphorus incorporation in the diamond singleepilayer. For such phosphorus content $\left(>3 \times 10^{18} \mathrm{at} / \mathrm{cm}^{3}\right)$, it is no longer possible to quantify precisely the donor concentration. ${ }^{36}$ The spectrum still shows narrow bound exciton $\mathrm{P}^{0} \mathrm{X}_{\mathrm{TO}}$ lines $(\sim 10 \mathrm{meV})$ and no-phonon $\mathrm{P}^{0} \mathrm{X}_{\mathrm{NP}}$ lines $(\sim 6 \mathrm{meV})$. This proves the good quality of the (113) diamond layers over a wide range of phosphorus doping (from $7.2 \times 10^{16}$ up to $3.2 \times 10^{19}$ at $/ \mathrm{cm}^{3}$ ).
In this work, we demonstrate the possibility to grow (113)-oriented phosphorus-doped homoepitaxial diamond layers with full incorporation of phosphorus atoms in donor sites, good crystalline quality, and low surface roughness, comparable to the best (100) and (111) phosphorus doped CVD diamond. The (111)-like growth conditions that involve a lower amount of methane but also with a lower growth rate appear to be the most suited to the (113) surface, contrary to the (100)-like growth conditions. This differs from previous reports on intrinsic and boron doped (113) epilayers. The maximum content and the incorporation efficiency found for phosphorus are between the values reached in (100) and (111) orientations. The (113) diamond layers retain high crystalline quality over nearly 3 decades of phosphorus content. These results pave the way for the fabrication of bipolar devices on (113) surfaces and open new perspectives for diamond growth engineering.

This work was financially supported by the National Research Agency (ANR) through the French National Project MOVeToDiam No. ANR-17-CE05-0019-02.

\section{REFERENCES}

${ }^{1}$ S. Shikata, "Single crystal diamond wafers for high power electronics," Diamond Relat. Mater. 65, 168 (2016).

${ }^{2}$ S. A. Bogdanov, A. L. Vikharev, M. N. Drozdov, and D. B. Radishev, Diamond Relat. Mater 74, 59 (2017).

${ }^{3}$ S. Ohmagari, H. Yamada, H. Umezawa, N. Tsubouchi, A. Chayahara, and Y. Mokuno, Diamond Relat. Mater. 81, 33 (2018).

${ }^{4}$ J. Achard, R. Issaoui, A. Tallaire, F. Silva, J. Barjon, F. Jomard, and A. Gicquel, Phys. Status Solidi A 209, 1651 (2012).

${ }^{5}$ H. Kato, M. Ogura, T. Makino, D. Takeuchi, and S. Yamasaki, Appl. Phys. Lett. 109, 142102 (2016).

${ }^{6}$ C. Gong, S. Li, H. Zhang, T. Su, M. Hu, H. Ma, X. Ji, and Y. Li, Int. J. Refract. Met. Hard Mater. 66, 116 (2017).

${ }^{7}$ V. Nadolinny, A. Komarovskikh, Y. Palyanov, and A. Sokol, Phys. Status Solidi A 212(11), 2568 (2015).

${ }^{8}$ M.-A. Pinault-Thaury, B. Berini, I. Stenger, E. Chikoidze, A. Lusson, F. Jomard, J. Chevallier, and J. Barjon, Appl. Phys. Lett. 100, 192109 (2012).

${ }^{9}$ S. Koizumi, M. Kamo, Y. Sato, H. Ozaki, and T. Inuzuka, Appl. Phys. Lett. 71(8), 1065 (1997).

${ }^{10}$ S. Koizumi, T. Teraji, and H. Kanda, Diamond Relat. Mater. 9, 935 (2000).

${ }^{11}$ T. Kociniewski, M.-A. Pinault, J. Barjon, F. Jomard, J. Chevallier, and C. Saguy, Diamond Relat. Mater. 16, 815 (2007).

${ }^{12}$ M.-A. Pinault-Thaury, T. Tillocher, D. Kobor, N. Habka, F. Jomard, J. Chevallier, and J. Barjon, J. Cryst. Growth 335, 31 (2011).

${ }^{13}$ H. Kato, S. Yamasaki, and H. Okushi, Appl. Phys. Lett. 86, 222111 (2005).

${ }^{14}$ T. Yamamoto, S. D. Janssens, R. Ohtani, D. Takeuchi, and S. Koizumi, Appl. Phys. Lett. 109, 182102 (2016).

${ }^{15}$ T. Kociniewski, J. Barjon, M.-A. Pinault, F. Jomard, A. Lusson, D. Ballutaud, O. Gorochov, J. M. Laroche, E. Rzepka, J. Chevallier, and C. Saguy, Phys. Status Solidi A 203(12), 3136 (2006).

${ }^{16}$ H. Kato, T. Makino, S. Yamasaki, and H. Okushi, J. Phys. D: Appl. Phys. 40, 6189 (2007).

${ }^{17}$ N. Temahuki, R. Gillet, V. Sallet, F. Jomard, E. Chikoidze, Y. Dumont, M.-A. Pinault-Thaury, and J. Barjon, Phys. Status Solidi A 214, 1700466 (2017).

${ }^{18}$ T. Nakai, O. Maida, and T. Ito, Appl. Surf. Sci. 254, 6281 (2008).

${ }^{19}$ O. Maida, S. Tada, H. Nishio, and T. Ito, J. Cryst. Growth 424, 33 (2015).

${ }^{20}$ M. Hasegawa, T. Teraji, and S. Koizumi, Appl. Phys. Lett. 79(19), 3068 (2001).

${ }^{21}$ F. Silva, J. Achard, X. Bonin, O. Brinza, A. Michau, A. Secroun, K. De Corte, S. Felton, M. Newton, and A. Gicquel, Diamond Relat. Mater. 17, 1067 (2008).

${ }^{22}$ M. Lesik, T. Plays, A. Tallaire, J. Achard, O. Brinza, L. William, M. Chipaux, L. Toraille, T. Debuisschert, A. Gicquel, J.-F. Rocha, and V. Jacques, Diamond Relat. Mater. 56, 47 (2015). 
${ }^{23}$ A. Tallaire, A. Valentin, V. Mille, L. Williama, M.-A. Pinault-Thaury, F. Jomard, J. Barjon, and J. Achard, Diamond Relat. Mater. 66, 61 (2016).

${ }^{24} \mathrm{~J}$. Achard and A. Tallaire, in Power Electronics Device Applications of Diamond Semiconductors, edited by S. Koizumi, H. Umezawa, J. Pernot, and M. Suzuki (Woodhead Publishing, 2018), Part 1.1, pp. 1-26.

${ }^{25}$ M.-A. Pinault-Thaury, I. Stenger, F. Jomard, J. Chevallier, J. Barjon, A. Traore, D. Eon, and J. Pernot, Phys. Status Solidi A 212(11), 2454 (2015).

${ }^{26} \mathrm{~J}$. Barjon and K. Haenen, in Power Electronics Device Applications of Diamond Semiconductors, edited by S. Koizumi, H. Umezawa, J. Pernot, and M. Suzuki (Woodhead Publishing, 2018), Part 2.4, pp. 154-173.

${ }^{27}$ Y. Balasubramaniam, P. Pobedinskas, S. D. Janssens, G. Sakr, F. Jomard, S. Turner, W. Dexters, A. Soltani, J. Verbeeck, J. Barjon, M. Nesladek, and K. Haenen, Appl. Phys. Lett. 109, 062105 (2016).

${ }^{28}$ T. Matsumoto, H. Kato, T. Makino, M. Ogura, D. Takeuci, H. Okushi, and A. Yamasaki, Jpn. J. Appl. Phys., Part 1 53, 05 FP05 (2014).
${ }^{29}$ H. Kato, T. Makino, M. Ogura, N. Tokuda, H. Okushi, and S. Yamasaki, Appl. Phys. Express 2, 055502 (2009).

${ }^{30}$ T. A. Grotjohn, D. T. Trana, M. K. Yaranb, S. N. Demlow, and T. Schuelke, Diamond Relat. Mater. 44, 129 (2014).

${ }^{31}$ N. Teofilov, R. Sauer, K. Thonke, and S. Koizumi, Physica B 340-342, 99 (2003).

${ }^{32}$ K. Nakazawa, K. Tanabe, M. Tachiki, H. Kawarada, and S. Koizumi, Phys. Rev B 64, 235203 (2001).

${ }^{33}$ H. Sternschulte, K. Thonke, R. Sauer, and S. Koizumi, Phys. Rev. B 59(20), 12924 (1999)

${ }^{34}$ H. Kato, J. Barjon, N. Habka, T. Matsumoto, D. Takeuchi, H. Okushi, and S. Yamasaki, Diamond Relat. Mater. 20, 1016 (2011).

${ }^{35}$ R. Sauer, N. Teofilov, K. Thonke, and S. Koizumi, Phys. Status Solidi A 201(11), 2405 (2004).

${ }^{36}$ J. Barjon, P. Desfonds, M.-A. Pinault, T. Kociniewski, F. Jomard, and J. Chevallier, J. Appl. Phys. 101, 113701 (2007). 